
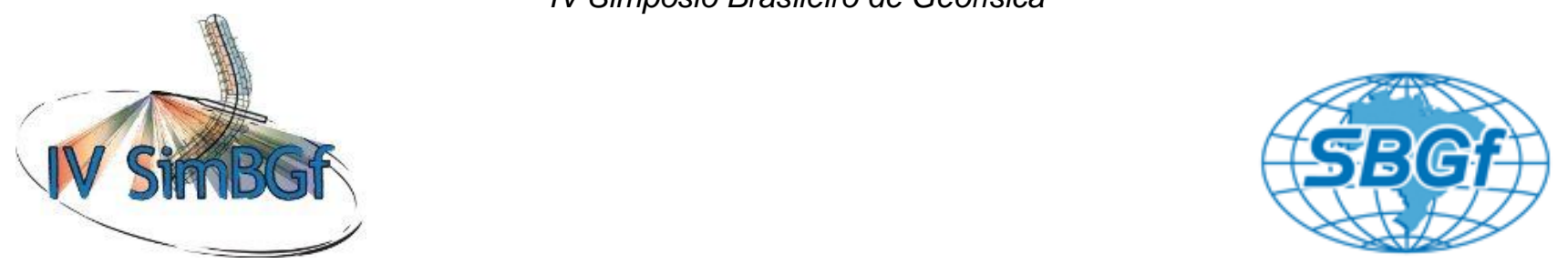

\title{
Integração de dados aerogeofísicos e do sensor ALOS no controle das mineralizações auríferas da região do Greenstone Belt de Guarinos e Pilar de Goiás.
}

*Kleyver Lenno da Paixão Ataíde; Mônica Giannoccaro Von Huelsen; Claudinei Gouveia de Oliveira; Henrique Llacer Roig, Universidade de Brasília-UnB; Karla Munique da Silva Pereira, Petrobras S.A.

Copyright 2010, SBGf - Sociedade Brasileira de Geofísica

Este texto foi preparado para a apresentação no IV Simpósio Brasileiro de Geofísica, Brasília, 14 a 17 de novembro de 2010. Seu conteúdo foi revisado pelo Comitê Técnico do IV SimBGf, mas não necessariamente representa a opinião da SBGf ou de seus associados. É proibida a reprodução total ou parcial deste material para propósitos comerciais sem prévia autorização da SBGf.

\section{Resumo}

A integração dos dados aerogeofísicos e do sensor ALOS (Advanced Land Observing Satellite) constituem produtos realçados, os quais mostram os relacionamentos espaciais entre morfologia do terreno e radioatividade do substrato, que são indicadores valiosos da distribuição de unidades litológicas, estruturas, tipos de rochas e processos de metassomatismo hidrotermal. A integração desses dados, baseados em imagens orbitais de sensores remotos e de dados aerogeofísicos, apresentou-se como uma ótima ferramenta para o mapeamento geológco na área dos Greenstone Belts de Guarinos e Pilar de Goiás.

\section{Introdução}

Os greenstone belts arqueanos de Goiás estão situado na província Tocantins na porção central do Brasil, a noroeste do maciço de Goiás, possuindo orientação NESW (Figura 1). A região do maciço de Goiás, onde estão situados esses greenstones, é caracteriza pela associação de greenstone belts e complexos granitognáissicos, a porção meridional contém dois greenstone belts, Faina e Serra de Santa Rita, e pelo menos um complexo granito-gnáissico (Uvá) e talvez uma parte de outro (Caiçara), já na porção setentrional, há a predominância de três greenstone belts (Crixás, Guarinos e Pilar de Goiás) e quatro complexos (Anta, Caiamar, Moquém e Hidrolina).

Diversos trabalhos foram realizados na área de estudo ao longo dos anos, mas uma integração de informações, utilizando dados aerogeofísicos e dados de sensoriamento remoto, se fez necessário para a realização de um melhor mapeamento de domínios geológicos, bem como um melhor entendimento da evolução geológica da área dos dois greenstones em questão, o de Pilar de Goiás e o de Guarinos.

As imagens aerogeofísicas utilizadas (magnetometria e gamaespectrometria) foram de suma importância no estudo dessas áreas, tanto no âmbito geológicoestrutural quanto no âmbito mineralizador. Esse último verificado pela técnica do potássio anômalo, onde as ocorrências auríferas, tanto de Guarinos quanto de Pilar de Goiás, estão associadas aos processos de hidrotermalismo. Uma síntese das características dos depósitos auríferos da região, também, foi de suma importância para auxiliar no entendimento do comportamento de algumas dessas respostas radiométricas.

As mineralizações auríferas, de modo geral, estão distribuídas ao logo de lineamentos estruturais de direções preferências NW/SE.

Dos dados de sensoriamento remoto foi utilizado o sensor PRISM (Panchromatic Remote-sensing Instrument for Stereo Mapping), do satélite ALOS, bem como, o modelo digital de elevação de terreno da missão SRTM (Shuttle Radar Topographic Mission). O sensor PRISM foi usado para a obtenção do detalhamento das feições geológicas lineares a partir de imagens estereoscópicas da área de estudo, já do modelo digital de elevação do terreno (SRTM), com resolução espacial de $30 \mathrm{~m}$, serviu como um suporte para a interpretação, não apenas da imagem PRISM, mas como dos dados aerogeofísicos gerados.

O resultado obtido com essa integração de informações possibilitou um melhor entendimento sobre 0 comportamento geológico-estrutural da área estudada, bem como da mineralização aurífera ocorrente, permitindo dentre outras coisas, um avanço no detalhe cartográfico.

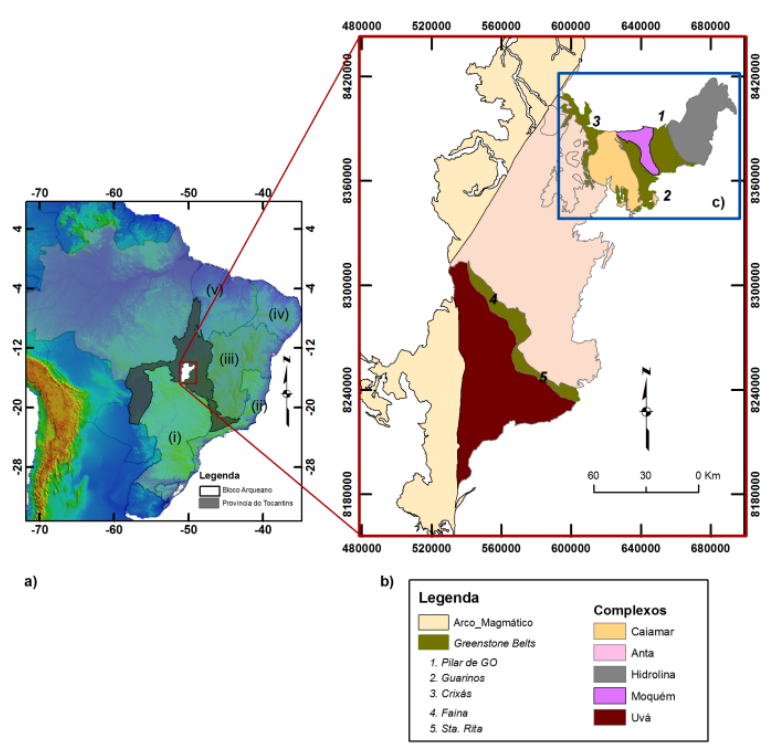


Figura 1 - a) Mapa de províncias tectônicas da América do Sul: (i) Província do Paraná; (ii) Província da Mantiqueira; (iii) Província do São Francisco; (iv) Borborema e (v) do Parnaíba. b) mapa destacando o Bloco Arqueano de Goiás com seus limites e subdivisões (em greenstones e complexos) e c) Mapa simplificado da região da Província Crixás.

\section{Metodologia/ Problema Investigado}

\section{Processamento}

A execução do trabalho obedeceu às seguintes seqüências:

Etapa I: Dados aerogeofísicos (magnetometria e gamaespectrometria): a área do trabalho é recoberta pelos dados dos projetos "Arco Magmático de Mara Rosa" e "Paleo-Neoproterozóico do Nordeste de Goiás" correspondentes à $1^{\underline{a}}$ e $3^{\underline{a}}$ etapa, respectivamente, do 'Projeto de levantamento aerogeofísico do Estado de Goiás'. Que abrangeu o período de 2004 a 2006. Com recorte cartográfico na escala de 1:25.000. Foram processados dados gamaespectrométricos e magnetométricos, com ambos possuindo sobrevôo a $100 \mathrm{~m}$ de altitude, linhas espaçadas de $0,5 \mathrm{~km}$, e linhas de controle a cada $5 \mathrm{Km}$. A direção das linhas de vôo é $\mathrm{N}-\mathrm{S}$ e das linhas de controle é E-W (Hildenbrand (org), 2006). Os dados gamaespectrométricos aéreos ( $\mathrm{K}$ em \%; $\mathrm{U}$ e Th em PPM) foram processados e a partir destes, foram gerados produtos em imagens ternárias, razões (K/U, K/Th e U/Th), contagem total em cps (CT) e K anômalo que facilitaram a detecção de corpos graníticos e de possíveis zonas de alteração hidrotermal. Os dados magnetométricos, foram igualmente processados e gerados produtos, tais como a Amplitude do Sinal Analítico (ASA), a Amplitude do Gradiente Horizontal Total (AGHT), Inclinação do Sinal Analítico (ISA) e a $1^{\text {a }}$ Derivada Vertical (DZ), que serviram na extração de feições lineares e domínios magnéticos. Somados a esses produtos, foi obtido também a Deconvolução de Euler com índices estruturais 0 e $1 \mathrm{com}$ a finalidade de se obter tanto os contatos geológicos quanto as feições lineares, respectivamente.

As imagens gamaespectrométricas escolhidas foram: o padrão RGB e a de contagem total (Figura 2 A e B), pois segundo Vasconcellos et al. (1994), essa apresenta maior precisão estatística fornecendo uma correlação maior das unidades radiométricas com as litologias, além de apresentar resultados mais eficientes na discriminação das unidades litológicas. Para a magnetometria, a imagem que melhor representa o resultado foi a AGHT, para a discriminação de lineamentos e contatos de corpos magnéticos (Figura 3).
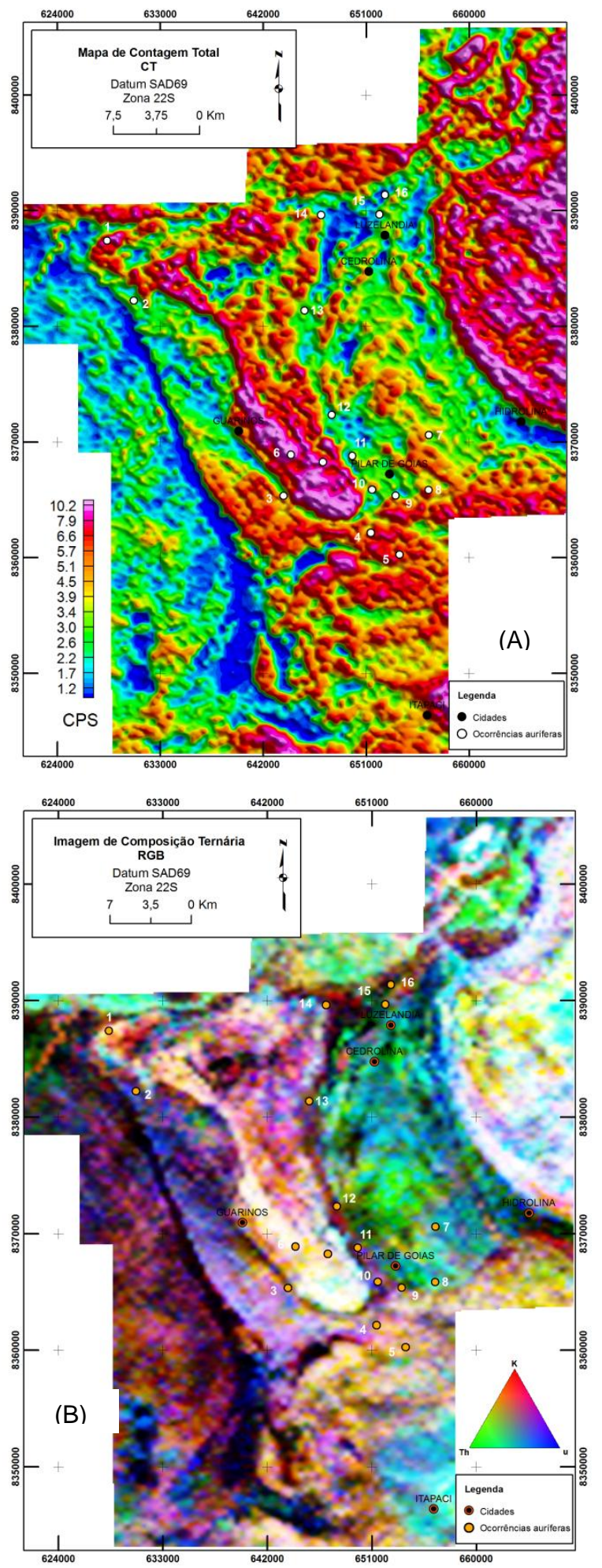

Figura 2 - Ocorrências auríferas primárias sobrepostas a imagem de (A) Contagem Total e (B) RGB: [(1) garimpo José Candido; (2) Caiamar; (3) Mária Lázara; (4) garimpo do Carlão; (5) garimpo Joaquim Isidoro; (6) garimpo do Jair; (7) garimpo Pilar de Goiás-saída Hidrolina; (8) garimpo Pilar de Goiás; (9) depósito Jordino; (10) depósito de Cachoeira do Ogó; (11) depósito Toti-Três 
Kleyver Lenno da Paixão Ataíde, Mônica Giannoccaro Von Huelsen, Claudinei Gouveia de Oliveira, Henrique Llacer Roig, 3 Karla Munique da Silva Pereira

Buracos; (12) garimpo Fazenda Moinho; (13) Morro do Tenente; (14) garimpo Morro da Cacunda; (15) garimpo Luzelândia; (16) garimpo Luzelândia].

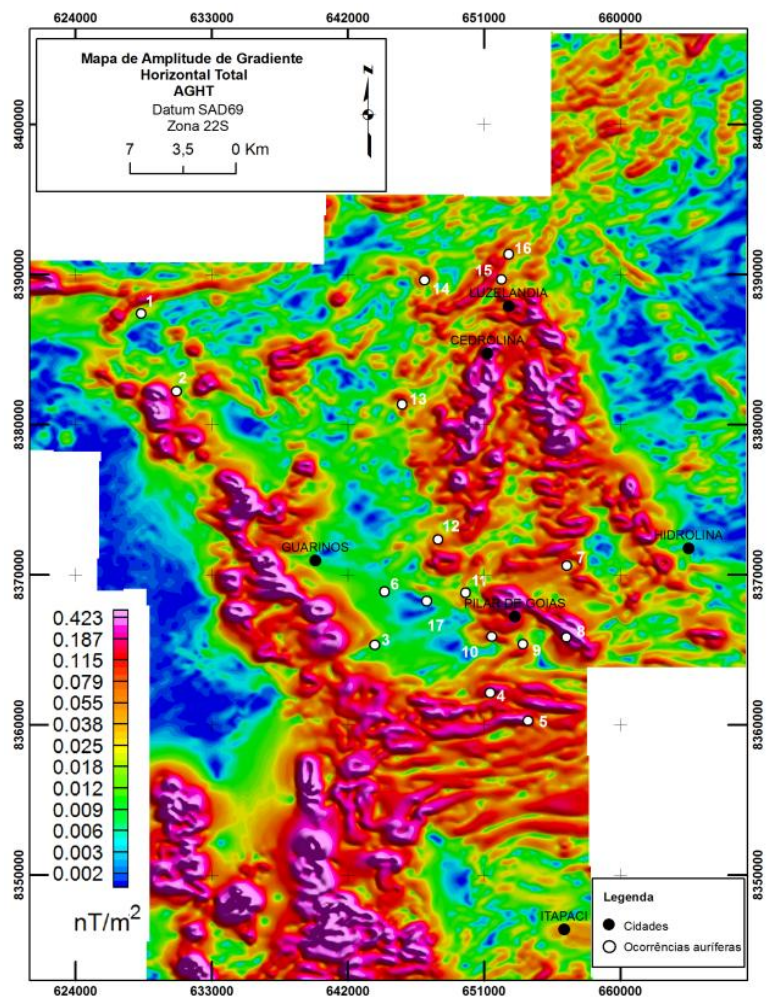

Figura 3 - Ocorrências auríferas primárias sobrepostas a imagem de AGHT: [(1) garimpo José Candido; (2) Caiamar; (3) Mária Lázara; (4) garimpo do Carlão; (5) garimpo Joaquim Isidoro; (6) garimpo do Jair; (7) garimpo Pilar de Goiás-saída Hidrolina; (8) garimpo Pilar de Goiás; (9) depósito Jordino; (10) depósito de Cachoeira do Ogó; (11) depósito Toti-Três Buracos; (12) garimpo Fazenda Moinho; (13) Morro do Tenente; (14) garimpo Morro da Cacunda; (15) garimpo Luzelândia; (16) garimpo Luzelândia].

Etapa II: Dados do Sensor ALOS (Advanced Land Observing Satellite): O ALOS é um satélite lançado em janeiro de 2006 pela Agência Espacial Japonesa (Jaxa). Descreve órbita circular com $692 \mathrm{~km}$ de altitude com período de revisita de 46 dias. Está equipado com 03 sensores imageadores: PRISM (Panchromatic Remotesensing Instrument for Stereo Mapping) capaz de adquirir imagens tridimensionais da superfície terrestre; AVNIR-2 (Advanced Visible and Near Infrared Radiometer type 2) para precisa cobertura terrestre e o PALSAR (Phased Array type L-band Synthetic Aperture Radar) capaz de obter imagens diurnas e noturnas sem a interferência de nebulosidade. No presente trabalho, foi-se utilizado o sensor PRISM para a obtenção do detalhamento das feições geológicas lineares a partir de imagens estereoscópica da área de estudo.

\section{Resultados}

Para a elaboração do mapa geológico, além das feições de relevo e drenagem analisadas na imagem PRISM, que são indicativas de estruturas tectônicas e contatos litoestruturais, foram consideradas também, na delimitação dos contatos e na discriminação das litologias, as respostas radiométricas do canal de contagem total, composições Ternárias (RGB e CMY) além de potássio Anômalo.

A delimitação das unidades litoestruturais no produto integrado, incluindo os contatos, levou em consideração não somente as respostas gamaespectrométricas, mas principalmente as feições texturais de relevo e drenagem fornecidas pela imagem ALOS e informações magnetométricas, tais como ASA, ISA, AGHT, DZ e Euler. Foi elaborado um mapa de domínios gamaespectrométricos, de lineamentos magnéticos e posteriormente, foram discriminados alguns domínios da área de estudo. A Figura 4 apresenta 0 produto integrado PRISM e contagem total, com as ocorrências auríferas em destaque.

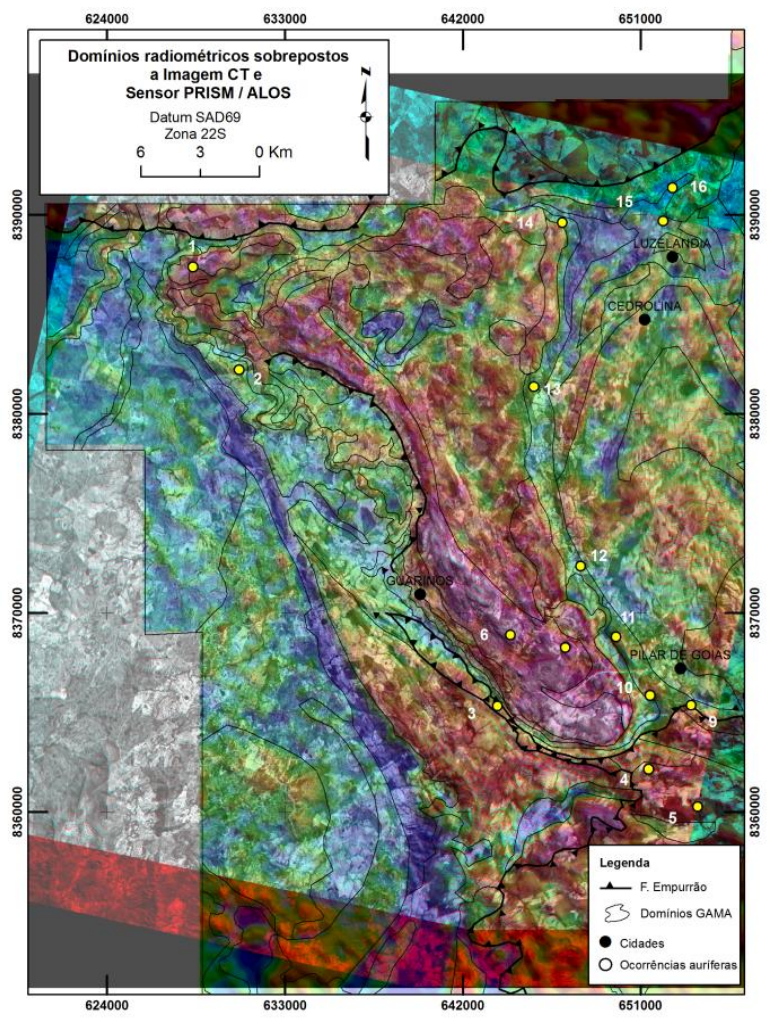

Figura 4. Produto integrado de Imagem de Contagem Total com a imagem do sensor PRISM (ALOS) do greenstone belt de Guarinos e Bloco Moquém com destaque as ocorrências auríferas [(1) garimpo José Candido; (2) Caiamar; (3) Mária Lázara; (4) garimpo do Carlão; (5) garimpo Joaquim Isidoro; (6) garimpo do Jair; (7) garimpo Pilar de Goiás-saída Hidrolina; (8) garimpo Pilar de Goiás; (9) depósito Jordino; (10) depósito de Cachoeira do Ogó; (11) depósito Toti-Três Buracos; (12) garimpo Fazenda Moinho; (13) Morro do Tenente; (14) 
garimpo Morro da Cacunda; (15) garimpo Luzelândia; (16) garimpo Luzelândia].

Dos produtos aeromagnetométricos gerados (ASA, ISA, AGHT e Dz), foram extraídas estruturas lineares correspondentes aos lineamentos magnéticos visíveis (Figura 6). Estas extrações foram, posteriormente, sobrepostas a imagem PRISM para se obter um maior detalhe das estruturas. Do produto AGHT objetivou-se o delineamento de feições estruturais, contatos entre corpos e descontinuidades.

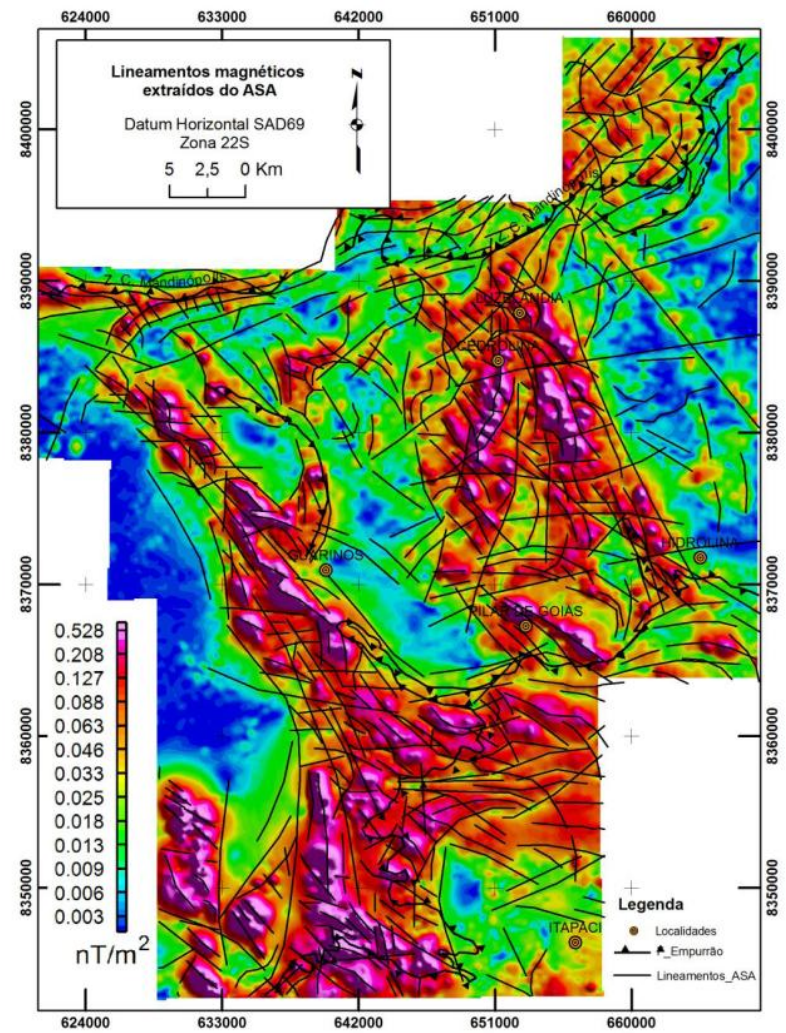

Figura 6. Lineamentos magnéticos extraídos da imagem ASA sobrepostos a imagem ASA, onde nota-se visivelmente os sistemas de empurrões ao norte e ao sul dos dois greenstones arqueanas (Guarinos e Pilar de Goiás), bem como as zonas de cisalhamentos que separam os complexos graníticos (representado por alto $U$ e baixo $K$ ) dos greenstones (representados pela alta resposta em $\mathrm{K}$ e baixo $U$ ).

Foi aplicada a técnica do potássio anômalo para ajudar na identificação de áreas hidrotermalizadas com expressão na superfície (Figura 8A). Juntamente com o potássio anômalo, foram empregadas as razões ( Th/ $\mathrm{K}$, $\mathrm{U} / \mathrm{K}$ e (U/Th), para ressaltar um radioelemento em relação a outro e para criar contraste em regiões onde ocorreram processos de hidrotermalismo (Figura 5).

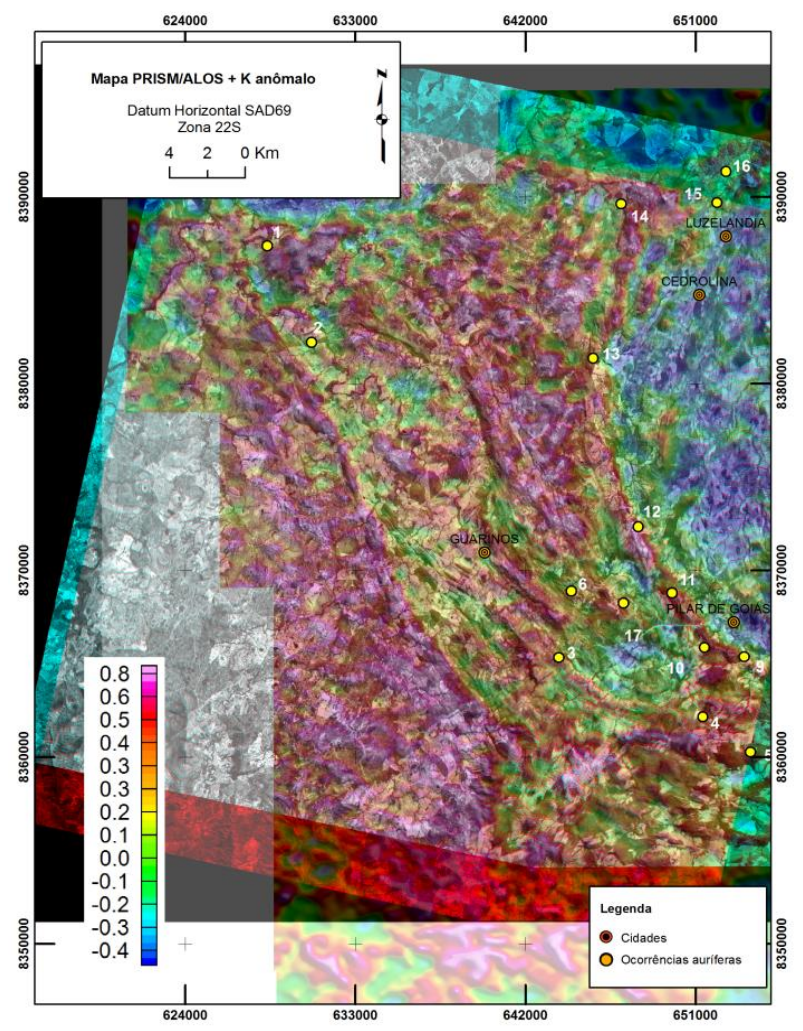

Figura 7. Imagem de K Anômalo sobreposto a imagem PRISM/ALOS. Em destaque as ocorrências auríferas primárias [(1) garimpo José Candido; (2) Caiamar; (3) Mária Lázara; (4) garimpo do Carlão; (5) garimpo Joaquim Isidoro; (6) garimpo do Jair; (7) garimpo Pilar de Goiás-saída Hidrolina; (8) garimpo Pilar de Goiás; (9) depósito Jordino; (10) depósito de Cachoeira do Ogó; (11) depósito Toti-Três Buracos; (12) garimpo Fazenda Moinho; (13) Morro do Tenente; (14) garimpo Morro da Cacunda; (15) garimpo Luzelândia; (16) garimpo Luzelândia].

\section{Discussão e Conclusões}

Com base nos produtos gerados após o processamento, interpretação e integração dos dados, conclui-se que:

1 - Quanto ao método:

A integração digital das informações mostrou-se excelente para o mapeamento geológico e de detalhe dos greenstones belts de Guarinos e Pilar de Goiás. O produto integrado final delimitou bem as feições texturais de relevo, drenagens, bem como, as feições estruturais mais marcantes da área;

2 - Quanto a aerogeofísica:

- As imagens aerogamaespectrométricas foram de grande valia para o mapeamento geológico. Dentre os produtos gerados, a composição ternária (RGB e CMY) permitiu uma melhor distinção entre os grandes domínios identificados, já uma integração de imagens MDT + CMY + contagem total permitiu obter uma boa distinção dos limites dos corpos (Figura 8B); 
Kleyver Lenno da Paixão Ataíde, Mônica Giannoccaro Von Huelsen, Claudinei Gouveia de Oliveira, Henrique Llacer Roig, 5 Karla Munique da Silva Pereira

- As concentrações relativas de radioelementos variam conforme o previsto na área de estudo, ou seja, maiores teores de radioelementos correspondem a rochas com maiores concentrações de sílica, ao passo que as ocorrências de corpos máficos estão associadas a sítios de baixa concentração;

\section{3 - Quanto à geologia:}

- Apesar da integração dos dados ter se mostrado bastante eficiente no mapeamento geológico se fez necessário verificar a influência de vegetação, topografia, solo exposto, através de análises quantitativas das respostas radiométricas, para que a geologia não fosse interpretada erroneamente. A resposta radiométrica de contagem total está diretamente relacionada com a composição química e mineralógica das rochas. Nem a presença de atividade antrópica e nem a variação de relevos mascaram o papel controlador da litologia nas respostas gamaespectrométricas;

- O trabalho realizado também permitiu registrar alguns aspectos novos nos terrenos arqueanos, porém o entendimento do conteúdo litológico, estratigráfico e estrutural completo dos mesmos carece de um mapeamento geológico bem mais detalhado. A integração dos dados permitiu definir que os limites da Zona de Cisalhamento Mandinópolis com a Seqüência Santa Terezinha possuem unidades com características até então pouco delimitadas e que abrem novas perspectivas para um melhor entendimento do seu conteúdo e significado tectônico.

- Em virtude da complexidade geológica do terreno e da escala das estruturas observadas, apenas um levantamento estrutural detalhado permitirá a elaboração de um melhor modelo estrutural bem como um mapeamento geológico para se delimitar de forma mais precisa os contatos litológicos. Porém, cabe ressaltar que apenas através dos dados aerogeofísicos, em especial a aeromagnetometria, foi possível a caracterização do padrão estrutural, que permite uma nova contribuição para a compreensão da evolução geológica da região;
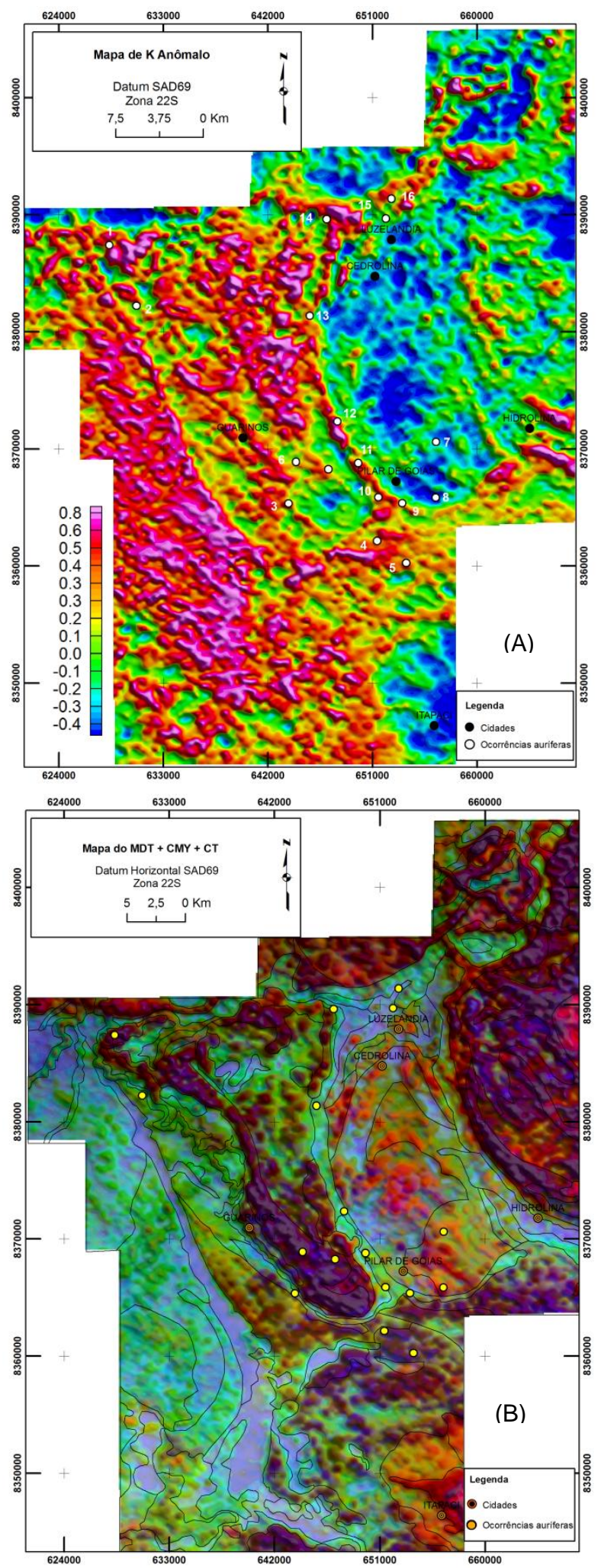

Figura 8. a) imagem do Potássio anômalo e b) Domínios radiométricos sobrepostos aos produtos $C T+M D T+C M Y$. Em destaque as ocorrências auríferas primárias. 
- As unidades onde estão presentes as ocorrências auríferas de Maria Lázara (Formação Serra Azul, no greenstone de Guarinos) e do trend JOT (Formação Serra do Moinho, no greenstone de Pilar de Goiás) apresentam respostas radiométricas muito similares, porém ambas as formações possuem composições litológicas distintas, isso se deve a presença de filonitos próximos ao metabasaltos, na Formação Serra Azul, e as metagrauvacas, que estão presentes na Formação Serra do Moinho, estarem bem próximas ao contato com os granito-gnaisse e os gnaisse granodiorítico do bloco Moquém. Os filonitos ocorrem, também, na base do Grupo Serra da Mesa. Esses filonitos e metagrauvacas mencionados entraram em contato com o bloco Moquém, onde encontram-se altamente influenciados pela ocorrência do hidrotermalismo que atuou nos locais, remobilizando os elementos e, por fim, gerando as ocorrências auríferas já mencionadas. Na porção setentrional da área, ocorre uma resposta radiométrica similar ao mencionado, porém em uma faixa deformada de milonitos que ocorre próximo a zona de cisalhamento Mandinópoles no limite com a seqüência Santa Terezinha;

\section{Agradecimentos}

- A Universidade de Brasília e ao Instituto de Geociências da UnB;

- Ao CNPq;

- Aos Professores Dr. Henrique Llacer Roig, Claudinei Gouveia, Raul Minas Kuyumjian, Mônica Giannoccaro Von Huelsen e Hardy Jost;

- Aos meus entes queridos.

\section{Referências}

Hildenbrand, J. D. (Org). 2006. Relatório final do levantamento e processamento dos dados magnetométricos e gamaespectrométricos. Levantamento Aerogeofísico do Estado de Goiás, Área5. Projeto Paleo-Neoproterozóico do Nordeste de Goiás, Texto técnico. Lasa Engenharia e Prospecções S.A. $128 \mathrm{p}$.

Vasconcellos, R.M.; Metelo, M.J.; Motta , A.C.M; Gomes, R.D. 1994. Geofísica em levantamentos geológicos no Brasil. Rio de Janeiro. CPRM, 165p. 